\title{
Contextualizando a Química: O Uso de Plantas Regionais na Contextualização de Conceitos Químicos
}

Ana Paula da Costa* (Graduanda em Química na Universidade Federal de Campina Grande (UFCG); José Carlos Oliveira Santos (Professor da UABQ/CES na Universidade Federal de Campina Grande (UFCG)

*E-mail: anaapaulacostaa@outlook.com

Resumo: É cada vez mais evidente a necessidade de se trabalhar com temas que tenham ligação entre o cotidiano do aluno e os conteúdos vistos em sala. Dessa maneira, utilizam-se ferramentas capazes de chamar a atenção do aluno, por estar abordando temas que o cercam, formando cidadãos mais críticos e capazes de tomar decisões e participarem ativamente da sociedade em que vivem. Este trabalho tem como objetivo o uso de plantas regionais na contextualização de conceitos químicos. As atividades foram divididas em quatro momentos, uma aula apresentando o tema e ressaltando as características gerais da árvore do juazeiro, uma aula falando sobre as propriedades físico-químicas e biológicas do juazeiro, uma aula relacionando alguns conceitos químicos que estavam ligados a escovação dos dentes com as raspas da casca do juazeiro e uma aula prática com a produção de um creme dental natural e a experimentação pelos alunos. Ao final foram escolhidos dois alunos que participaram de todo o desenvolvimento do projeto para apresentação de um trabalho na feira de ciências da escola, contribuindo para a formação dos alunos de forma positiva.

Pallavras-chave: Contextualização; ensino-aprendizagem; juazeiro; ensino de química

Espaço reservado para organização do congresso. 


\section{I ntrodução}

É cada vez mais evidente a necessidade de se fazerem diálogos que tenham ligação com situações cotidianas da vida do aluno com os próprios conteúdos de ensino, isto vem sendo defendido tanto por pesquisadores da área de ensino, mas como também pelos documentos oficiais de orientação curricular (WHARTA et al., 2013). Existe uma série de problemas ambientais que tem ligação direta com o desenvolvimento da ciência e da tecnologia, alguns desses problemas são o aumento do aquecimento global, as contaminações de aquíferos, as queimadas e desertificações de inúmeras áreas do planeta, a crescente escassez energética, os desequilíbrios biológicos e físico-químicos; entre vários outros problemas que ameaçam a vida no planeta terra, portanto não parece distante da realidade dos alunos trabalharem com temas que tenham ligação com esses problemas, inclusive já existe um ramo da química interessada nesses assuntos a química verde. Neste rumo é muito interessante que se propunham atividades que possam trabalhar estes temas, levando em consideração o contexto social em que o aluno está inserido (GUIMARÃES, 2009).

$\mathrm{Na}$ atualidade surgem novas portas para um futuro mais verde, com isso novos desafios são lançados para a ciência, a sustentabilidade ambiental é o grande desafio da atualidade, como se desenvolver sem destruir os recursos naturais? Como orientar novas práticas sociais, econômicas e políticas? Isto está diretamente ligado a práticas químicas e pedagógicas, e principalmente a formação teórica e prática dos profissionais dessa área. No entanto, a abordagem de problemas ambientais não é uma tarefa que cabe somente a química, é uma questão muito mais abrangente que cabe a uma mudança no modelo de desenvolvimento econômico e social, uma questão política e de caráter planetário. A química e as demais ciências exercem um papel singular, principalmente nos processos voltados para a cidadania, que infelizmente tem acontecido pouco nas salas de aula (ABREU e IAMAMOTO, 2003).

Para trabalhar estes temas em sala de aula é necessário primeiro fazer o aluno sentir a necessidade de conhecer esses temas, é preciso mostrar que ele faz parte desse processo e que as suas atitudes podem influenciar tanto de forma positiva quanto negativa. Nem todo tema que o aluno ver em sala de aula é interessante para ele, por isso é necessário problematizar e incluí-lo primeiro. Trabalhar esses temas implica na contribuição para formação de cidadãos mais críticos e capazes de opinar na sociedade em que vivem. As críticas que vem sendo feitas ao modelo de ensino tradicional estão ligadas justamente a isso. $\mathrm{O}$ fato de o aluno ouvir passivamente os conteúdos sem ser um agente ativo, ou não conseguir enxergar uma ligação do conteúdo visto em sala com algo que ele já sabe.

Geralmente as aulas expositivas do modelo tradicional de ensino tratam de temas que os alunos nunca tiveram acesso e por que não trazer problemas do seu cotidiano, instigando os alunos a procurarem soluções e a construírem seu próprio conhecimento, no ensino de ciências a experimentação pode ser uma ótima ferramenta para isso, desde que permita a contextualização e o estímulo a questionamentos. A metodologia para ser trabalhada tem que ser uma resposta aos questionamentos levantados pelos educandos, isto deve ser notado durante o período de interação durante o contexto criado em sala de aula.

É necessário que o aluno construa uma aprendizagem ancorando os conhecimentos que ele aprende nos que ele já tem, que ele construa uma aprendizagem significativa e não uma aprendizagem fragmentada. Para isso é necessário que o professor saiba o que o aluno já sabe e ensine com base nisso. A aprendizagem mecânica ou automática faz oposição a este tipo de aprendizagem, ela é aprendida sem que haja uma interação com o que o individuo já sabe, desta forma não contribui para uma aprendizagem significativa. O momento ideal para o professor observar o aprendizado do aluno é quando surge um problema ou um questionamento, pois para solucionar a questão levantada o aluno tem que ter algum conhecimento prévio. Levando em consideração essas descobertas feitas durante o curso da aula, o professor pode considerar as maiores dificuldades dos alunos e traçar métodos para uma aprendizagem mais significativa. No entanto para isso acontecer é preciso desafiá-los com problemas do seu meio social e motivá-los e ajudá-los a responder os problemas. As Ciências não podem ser ensinadas como algo inquestionável e o professor não pode ser tido como o dono da verdade, o que sabe tudo, isso dificulta a interação do aluno com o professor (MARQUES et al., 2007).

Este trabalho foi escrito com o intuito de contextualizar alguns conceitos químicos com o contexto social dos alunos. Foi escolhido trabalhar com o juazeiro por ser uma árvore nativa, 
popularmente conhecida na região e que foi muito usada pelos pais, avôs e os que antecederam os alunos, e muitos não conheciam suas fantásticas propriedades desde medicinais a anticépticas.

A aprendizagem da química deve possibilitar aos alunos capacidade de compreensão da química que está presente ao seu redor, para poder tomar decisões e aprender a interagir com o mundo que o cerca. Para isso acontecer de forma positiva é necessário que o professor consiga identificar os fatores que motivam os alunos, contextualizar os conteúdos químicos em sala e conscientizar os alunos da importância das ciências na sociedade ao seu redor. Mas vale a pena lembrar que contextualizar os conceitos químicos não é somente promover uma ligação artificial entre o que está sendo estudado em sala com o que o aluno vivencia no seu cotidiano, nem tão pouco citar alguns exemplos vagos, vai um pouco, além disso, é propor situações reais, concretas e acessíveis para os alunos e não somente é necessário também que o professor forneça ao aluno ferramentas necessárias para que ele possa investigar e solucionar os questionamentos levantados.

\section{Metodologia}

A abordagem desse projeto foi voltada para a exploração de uma cultura muito forte por parte dos mais velhos da região dos alunos, que é o uso da árvore do juazeiro, que serve desde comida para o gado até para higienizar a boca, servindo como creme dental. $\mathrm{O}$ intuito era mostrar para os alunos a química presente nesses processos que acontecem ao seu redor. O projeto foi desenvolvido na Escola Estadual de Ensino Médio Professor Lordão no município de Picuí localizado no estado da Paraíba no Brasil. A turma era composta por trinta e um alunos de turmas diferentes do primeiro, segundo e terceiro ano do ensino médio.

O trabalho foi dividido em partes, foram feitas algumas atividades a fim de explorar o máximo o tema, levando em consideração o conhecimento que os alunos já tinham sobre o tema, por se tratar de uma árvore conhecida na região não foi uma tarefa difícil. A primeira atividade a ser realizada foi uma aula sobre a árvore do juazeiro, mostrando suas características gerais, a segunda atividade foi uma aula mostrando as propriedades físico-químicas e biológicas da árvore, a terceira parte foi uma aula mostrando alguns conceitos químicos envolvidos com o juazeiro quando você escova os dentes com ele e a quarta parte foi o momento experimental onde foi feito um creme dental com as raspas do juazeiro e algumas ervas naturais, os alunos experimentaram o creme dental e por fim dois alunos foram escolhidos para escrever um resumo sobre o assunto para a feira de ciências do colégio e apresentarem.

\section{Resultados e Discussões}

Na primeira parte do projeto, onde foi apresentado o tema que iria ser trabalhado em sala, vários alunos afirmaram que conheciam a planta e inclusive alguns que moravam na zona rural conheciam uma planta próximo de casa. Os alunos da zona urbana a maioria tinha um avó, um tio, um parente que conhecia o local onde se podia encontrar a planta ou já tinham usado alguma vez na vida as raspas da casca da árvore para escovar os dentes. O primeiro momento do projeto foi muito proveitoso, algumas discussões se iniciaram com os alunos a respeito da árvore, eles contaram algumas experiências com a planta, ou alguma história que um parente contou. A primeira aula abordou a história do juazeiro no nordeste e sua importância para o nordestino nos períodos de seca.

Na segunda parte do projeto foram abordadas as propriedades físico-químicas e biológicas da planta. O intuito dessa aula era começar a introduzir os conceitos químicos que envolviam a planta, já que os mesmos só sabiam a respeito da planta suas propriedades populares, eles não tinham nenhum conhecimento científico a respeito da árvore do juazeiro. Foi mostrado para eles como foram feitos algumas análises físico-químicas da planta e seus resultados, e foram feitas algumas comparações com o resultado das análises com outras plantas. Na parte da aula que abrangia as propriedades biológicas da árvore do juazeiro foram mostradas algumas de suas propriedades medicinais e seu poder antiinflamatório; nessa parte do projeto os alunos se mostraram-se mais atentos, participaram menos talvez por não terem muito conhecimento a respeito do que estava sendo trabalhado.

Na terceira parte do projeto foi feito uma contextualização direta do que acontece quimicamente quando escovamos os dentes. Foram abordados alguns conceitos químicos como, por exemplo, o porquê as raspas da casca do juazeiro espuma em contato com a água, que substâncias 
estão presentes na árvore do juazeiro, nessa parte do projeto foi feito a relação direta com alguns conceitos químicos, com a finalidade de mostrar para os alunos que a química estudada em sala de aula está presente naquela árvore que alguns deles tinham no fundo do quintal e que seus avós usavam para escovar os dentes, ou no período de seca eles usavam para alimentar o gado, já que a árvore permanece verde mesmo nos períodos sem chuva.

Todo o período da realização do projeto foi muito prazeroso, os alunos interagiram e compartilharam suas experiências, em alguns momentos permaneceram mais calados, talvez para absorver mais informações, mais a quarta parte do projeto foi a mais interessante de todas, foi onde nos fizemos o creme dental natural à base da casca do juazeiro e de ervas naturais, e os alunos puderam experimentar, foi o momento em que colocamos tudo o que estudamos em prática, eles puderam observar de perto que as raspas da casca do juazeiro realmente espuma em contato com a água.

E para finalizar dois alunos que participaram do projeto foram escolhidos para escrever um resumo a respeito do projeto e apresentar na feira de ciências da escola. Os alunos escolhidos escreveram um resumo a respeito do projeto, o resumo foi aceito na feira de ciências e eles apresentaram o creme dental, a apresentação dos alunos foi ótima, eles conseguiram passar para os visitantes o que foi feito no projeto e que as raspas da casca da árvore poderia ser usada para escovar os dentes. Muitos dos visitantes conheciam a planta, inclusive usavam e ficaram felizes de aprender algumas de suas propriedades científicas.

\section{Conclusão}

Ao analisar o fim do projeto e os frutos que ele gerou percebeu-se que os alunos foram mais participativos nas aulas. $\mathrm{O}$ fato de se trabalhar com algo real, concreto e que eles tinham acesso fez com que eles se interessassem mais e se dedicassem mais ao que estava sendo passado. Foi bastante eficaz usar temas da realidade do aluno para se trabalhar, ou melhor, para contextualizar os conceitos químicos, pois os alunos assimilaram o que eles já sabiam com o que estava sendo aprendido. Eles já tinham um senso comum a respeito do tema e acabaram descobrindo os mitos e verdades a cerca do que ele já sabia. Durante o desenvolvimento do projeto buscou-se contextualizar o cotidiano do aluno com os conceitos químicos vistos em sala, para mostrar que a química estudada em sala de aula estava presente no cotidiano deles.

\section{Contextualizing Chemistry: The Use of Regional Plants in the Context of Chemical Concepts}

Albstract: It is increasingly the need to work more evident with themes that have connection between the daily life of the student and the contents seen in class. In this way, they use tools that can draw the attention of the student, to be addressing issues that surround it, forming more critical citizens able to make decisions and actively participate in the society in which they live. This work aims at the use of regional plants in the context of chemical concepts. The activities were divided into four stages, a lecture presenting the subject and emphasizing the general characteristics of the jujube tree, a class talking about the physical and chemical properties and biological juazeiro, a lesson by relating some chemical concepts that were linked to tooth brushing with jujube bark chips and a practical class with the production of a natural toothpaste and experimentation by students. At the end we chose two students who participated in the entire development of the project for submitting a job fair in school science, contributing to the training of students in a positive way. 


\section{Referências bibliográficas}

ABREU, D. G.; IAMAMOTO, Y. Relato de uma Experiência Pedagógica no Ensino de Química: Formação Profissional com Responsabilidade Ambiental. Química Nova, v. 26, n. 4, 2003.

GUIMARÃES, C. C. Experimentação no Ensino de Química: Caminhos e Descaminhos Rumo à Aprendizagem Significativa. Química Nova na Escola, v. 31, n. 3, 2009.

MARQUES, C. A.; GONÇALVES, F. P.; ZAMPIRON, E. Visões de meio ambiente e suas implicações pedagógicas no ensino de química na escola média. Química Nova, v. 30, n. 8, 2007.

WHARTA, E. J.; SILVA, E. L.; BEJARANO, N. R. B. C. Cotidiano e Contextualização no Ensino de Química. Química Nova na Escola, v. 35, n. 2, 2013. 